\title{
The retrieval of positive and negative information from short-term memory storage for use in a concept-identification task*
}

\author{
RICHARD H. WINNICK $\dagger$ and E. JAMES ARCHER \\ University of Rhode Island, Kingston, Rhode Island 02881
}

\begin{abstract}
Short-term memory for multidimensional visual stimuli was studied as a function of oral verbal labeling as positive or negative instances in a concept-identification task. Labels were delivered concurrently with the initial presentation of the instance and were "positive," "negative," or "no label." Short-term retention for the differently labeled stimuli was tested following an 8-sec rest interval with a same/different discrimination task. Response latencies were shortest for positively labeled instances and longest for negatively labeled instances. The results suggest a facilitation of short-term retention for information perceived as important by the problem solver and a degredation in performance for information perceived as unimportant.
\end{abstract}

Ss have been shown to operate more effectively in a concept-identification task with positive instances than with negative instances (Smoke, 1933). This differential ability persists when the information content of the instances is equated (Hovland \& Weiss, 1953). One explanation may be that Ss assume that positive information is more important than negative information and therefore pay more attention to it. It may be assumed that this preference develops because positive instances usually transmit more information than negative in everyday life (Hovland, 1952). This study proposes that this perceived importance (Harris \& Haber, 1963) would lead to differences in short-term memory (STM) storage, thus affecting the subsequent ease of information retrieval. It should be possible to selectively influence perceived importance and observe differences in retrieval from STM storage by labeling a stimulus as either a positive or negative instance and then testing the S's ability to retrieve the differently labeled stimuli.

In this study Ss were required to retrieve positively labeled, negatively labeled, and unlabeled stimuli, which were presented as instances in a concept-identification task from STM. They were then asked to compare a second stimulus to this retrieved information and make a same or different discrimination. To insure that the information was stored in STM, the stimuli were presented briefly $(1 \mathrm{sec})$, allowing only enough time for one overt repetition of the stimulus item. An 8-sec rest-interval task was inserted between the presentation of the instance and the test for retention to prevent rehearsal. The 8-sec time interval was selected to fall midway in the hypothesized storage limits of STM (Peterson \& Peterson, 1959). It is proposed that the time taken for the information to be retrieved from STM and utilized by the S should closely approximate the S's reaction time to the discrimination task, and that this

*The research was partially supported by Grant MH 21979-01 from the National Institute of Mental Health.

tRequests for reprints should be sent to Richard H. Winnick, Department of Psychology, University of South Carolina, Columbia, South Carolina 29208. time would reflect any differences in ease of retrieval of the differently labeled stimuli. It was hypothesized that Ss would process and store negatively labeled stimuli in a less efficient manner and that this would be evidenced in longer reaction times for the subsequent discrimination task.

\section{METHOD}

Two small adjoining rooms with a one-way glass wall between them were used for conducting the experiment. The S's room contained a vision tunnel before which the $S$ sat with two shields extending from the sides of the tunnel back past his head. The arrangement minimized distractions for the $\mathrm{S}$ and allowed him to focus his attention down the tunnel at the end of which was a 12 $x 12$ in. rear-projection screen. A response box, which consisted of a signal light and two response switches labeled "same" and "different," was located in the center at the front of the tunnel. Stimuli were projected from the adjoining room through the one-way glass onto the tunnel's projection screen. All projection, sequencing and timing apparatus, was located in the adjoining room to keep the S's room as distraction-free as possible. Communication between the $\mathrm{S}$ and the $\mathrm{E}$ was by means of an intercom system which allowed the $E$ to listen in on the $S$ at all times and to speak to the $S$ to orally label the projected stimuli. Tape-recorded instructions were played for the $S$ containing an explanation of positive and negative information and an example of how a problem could be solved using both. The $S$ was then told that he would be required to solve a concept-identification task with the information which would now be presented to him. No practice trials were given, as it has been demonstrated that Ss can adapt to the use of negative information with practice (Freibergs \& Tulving, 1961).

Stimuli were single cards from the Wisconsin Card Sort Test (WCST), and were projected by means of a $16-\mathrm{mm}$ single-frame advance, animation projector. The sequencing and timing of the projector was controlled by an electronic circuit designed around a Signettics 555 solid state circuitry chip and two multiple stepping relays. Accuracy of presentation on all intervals was achieved to $\pm .02 \mathrm{sec}$.

The sequence of presentation for a single discrimination task was a single card from the WCST projected for $1 \mathrm{sec}$. Simultaneous with the presentation, the $\mathrm{E}$ over the intercom labeled the stimulus as either a "positive" or "negative" instance or said nothing, i.e., silence. The instance was then replaced with eight successive frames, one at a time for $1 \mathrm{sec}$ each, of words of colors printed in noncorresponding colors, i.e., the well-known Stroop task. The $\mathrm{S}$ was required to say out loud the color of the 
Table 1

Discrimination Response Time (Seconds) as a Function of Labeling

\begin{tabular}{cc}
\hline Label & Mean Time \\
\hline Positive & 2.2386 \\
No Label & 2.3343 \\
Negative & 2.8516 \\
\hline
\end{tabular}

Note $-F(2,22)=5.884, p<.01$

ink the word was written in. This task was intended to prevent rehearsal of the WCST card. Following the eighth color word, another WCST card appeared and the S was required to make a same or different discrimination and respond by pushing one of the two switches provided for him. The S's response interval, from the time the second WCST card appeared until the S pushed one of the response switches, was measured by a Hewlett-Packard 5300A measurement system timer to the nearest $.0001 \mathrm{sec}$. This procedure was followed six times; two instances were labeled "positive," two were "negative," and two were not labeled. There were three "same" and three "different" discriminations in each cycle. The $\mathrm{S}$ went through this cycle of six discriminations six times for a total of 36 discriminations.

The order of labeling and discriminations was designed using 6 by 6 Latin squares to minimize the S's responding to order of conditions.

The Ss were 12 college students recruited from a class in abnormal psychology and were not paid for their participation.

\section{RESULTS}

S's response times were analyzed employing a repeated-measures analysis of variance technique. The mean number of correct responses was .82 and the range was from .64 to .94 responses correct. Response times ranged from .15014 to $4.4676 \mathrm{sec}$. The mean response times for different and same discriminations were $2.1169 \mathrm{sec}$ and $2.8326 \mathrm{sec}$, respectively, $\mathrm{F}(1,11)=7.29$, $\mathrm{p}<.05 .^{1}$

The effect of labeling on response time was found to differ significantly from fastest to slowest in the following order: positively labeled, unlabeled, and negatively labeled, $\mathrm{F}(2,22)=5.88, \mathrm{p}<.01$. These results are shown in Table 1.

Tukey's test for significant gaps indicated that the "negatively" labeled condition differs significantly from the "unlabeled" and "positively" labeled conditions, which do not differ significantly from each other, gap $>.51, \mathrm{p}<.05$.

The Type of Discrimination by Label interaction was not found to be significant at the .05 level, $F(2,22)=$ 1.67 .

\section{DISCUSSION}

The results of this study indicate that, in a college population, STM for multidimensional stimuli can be affected by the oral presentation of verbal labels concurrent with first stimulus presentation. If, in the context of a concept-identification task, the $\mathrm{S}$ was told that a visual stimulus was a positive instance, then $8 \mathrm{sec}$ later his memory, as measured by reaction time for a same or different judgment, was better (faster) than if the initial stimulus had been labeled as a negative instance.

A model which may account for these data would appeal to the concept of arousal in an attention focusing sense. If a "positive" label indicates to the $\mathrm{S}$ the instance is important, while a "negative" label indicates the instance is unimportant then the labeling may tee directly influencing the attention paid by the $S$ to the stimulus presented. The important information by definition being more altering, attention-getting. In the "no label" condition the S has the option to either "pay attention" to the information presented or not. 2

The S's perception of the importance of the information presented to him thus directly influences his ability to perform in a concept-identification task by influencing his ability to retain the information necessary to solve the problem. Information which is encoded while the organism is moderately aroused, attending, will be facilitated (Atkinson \& Shiffrin, 1968), while information which the $S$ perceives to be unimportant will elicit lower levels of attending and thus is less well remembered.

These findings suggest a possible explanation for the initial inability of Ss to perform adequately in concept-identification tasks using negative information and their later ability, with practice, to improve in their performance. Initially, Ss do not attend to information perceived as unimportant to them (negative instances) and thus do not store this information adequately. Later in the task, as Ss learn that negative information can be used efficiently to solve the problem, the perceived importance of negative information increases. This new perception of importance increases attending behaviors facilitating memory storage, thus allowing an increase in problem solving ability.

\section{REFERENCES}

Atkinson, R. C., \& Shiffrin, R. M. Human memory: A proposed system and its control processes. In $K$. W. Spence and J. T. Spence (Eds.), The psychology of learning and motivation. Vol. 2. New York: Academic Press, 1968.

Freibergs, V., \& Tulving, E. The effect of practice on utilization of information from positive and negative instances in concept identification. Canadian Journal of Psychology, 1961, 15. 101-106.

Harris, C. S., \& Haber, R. N. Selective attention and coding in visual perception. Journal of Experimental Psychology, 1963, 75, 328-333.

Hovland, C. I. A “communication analysis" of concept learning. Psychological Review, 1953, 59, 461-472.

Hovland, C. I., \& Weiss, W. Transmission of information concerning concepts through positive and negative instances. Journal of Experimental Psychology, 1953, 45, 165-182.

Peterson, L. E., \& Peterson, M. J. Short term retention of individual verbal items. Journal of Experimental Psychology, 1959, 58, 193-198.

Posner, M. I., Keele, S. W., \& Eichelman, W. H. Retention of visual information from a single letter. Journal of Experimental Psychology, 1969, 79, 1-16.

Smoke, K. L. Negative instances in concept learning. Journal of Experim ental Psychology, 1933, 16, 583-588.

\section{NOTES}

1. Contrary to Posner's research (1969), it was found that Ss can respond more quickly to different discriminations than to same discriminations. To make a "same" response, the $S$ had to check each and every dimension before responding, while for a "different" response it was only necessary to search until one dimension was found to be different.

2. Given the $S$ population used in this study it is not unreasonable to assume that unlabeled information was more often perceived as being important than unimportant. This assumption explains the lack of statistically significant differences between the no-label and positively labeled conditions.

(Received for publication January 28, 1974.) 